\title{
Investigation of the frequency of COVID-19 in patients treated with intravesical BCG
}

1. Sakarya University Faculty of Medicine Department of Infectious Diseases, Sakarya, Turkey 2. Sakarya University Education and Research Hospital, Department of Urology, Sakarya, Turkey 3. Sakarya University Faculty of Medicine, Department of Internal Medicine, Sakarya, Turkey

\section{SUMMARY}

INTRODUCTION: In this retrospective study, we aimed to investigate the frequency of COVID-19 in patients with and without BCG application due to bladder tumors.

METHODS: The presence of COVID-19 was investigated in 167 patients with BCG and 167 without bladder cancer. All patients were compatible with COVID-19 infection. Patients with RT-PCR positive for SARS-CoV-2 and/or Chest CT positive for viral pneumonia between March and May 2020 were included in the study.

RESULTS: A total of 334 patients were included in the study. The mean age of the 167 patients in the study group was $71.1 \pm 14.21$ (min. 38.0- max. 98.0 years), 141 (84.4\%) were male. The mean age of the 167 patients in the control group was $70.5 \pm 13.8$ years (min. $41.0-$ max. 96.0 years), and 149 were male ( $p>0.05)$. COVID-19 was detected in 5 patients in the BCG group and in 4 patients in the control group $(P>0.05)$.

CONCLUSION: Intravesical BCG administration does not decrease the frequency of COVID-19 infection.

KEYWORDS: COVID-19, Intravesical BCG

\section{INTRODUCTION}

The COVID-19 outbreak from SARS-CoV-2, which started in China in 2019, caused a pandemic all over the world. In this disease, serious damage can occur in many organs, especially the lungs (Figure 1). Different treatment options continue to be investigated for COVID-19. This infection, which still has no effective treatment, spreads from country to country, infecting new people. Despite all efforts on vaccine production, an effective vaccine has not been found so far. Therefore, efforts to increase the immunity of individuals are considered important. Some information has been published recently showing that the Bacillus Calmette Guerin (BCG) vaccine can be used in the treatment of COVID-19'. 


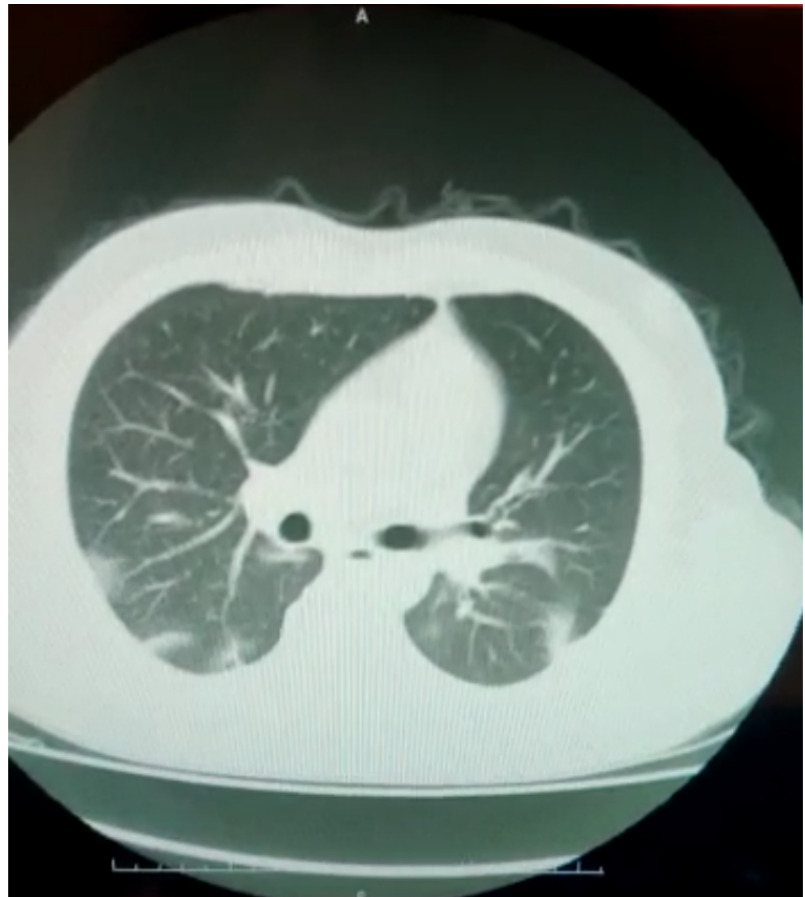

FIGURE: 1. COMPUTERIZED TOMOGRAPHY OF THE THORAXIN COVID-19 PATIENT

The BCG vaccine is a live bacterial vaccine from Mycobacterium bovis, which has been used to protect against tuberculosis for about a century. In the treatment of alternating bladder epithelial cell cancer, the BCG strain is administered into the bladder through a urethral catheter in high-risk patients to prevent relapse. BCG immunotherapy is applied in 6 doses for 6 weeks, for induction purposes, in non-muscle-invasive patients of high-risk (Figure 2). BCG therapy or any other immunoregulatory therapy is not used in patients with a tumor limited to the urothelium and classified as a low-risk ${ }^{2}$. After induction therapy, a maintenance treatment is given for 3 weeks, once a week with 6-month intervals for 3 years. The effect is non-specific stimulation, which takes a short time ${ }^{3}$.

However, it has been reported that immunity enhanced by BCG may provide efficacy against COVID$19^{3}$. Although the epidemiological relationship between BCG and COVID-19 is striking, it has not been tested in well-designed clinical trials. Therefore, in the absence of evidence, the BCG vaccine cannot be recommended to prevent COVID-19. The results of ongoing RCTs will guide us further. However, what is the frequency of COVID-19 in those who still have BCG inside the bladder due to bladder cancer? According to our information, there is no study on this subject. With this study, for the first time, the frequency of COVID-19 was investigated in patients with bladder cancer.

\section{METHODS}

Center: This study was done in a tertiary hospital with a 1100 - bed capacity. A total of $>2000$ patients were followed-up in this hospital during the COVID19 season.

The diagnosis of COVID-19 was based on the criteria of the Turkish National Health Commission. The COVID-19 data of all the patients included in the study were obtained from the hospital information system retrospectively. All the patients were compatible with COVID-19 infection. Patients with RT-PCR positive for SARS-CoV-2 and/or Chest CT positive for viral pneumonia between March and May 2020 were included in the study.

Patients: We included those with no additional disease affecting the immune system, followed up by the Sakarya University Urology clinic and diagnosed with non-muscle-invasive, altered epithelial cell bladder cancer. This descriptive retrospective cross-sectional study was conducted with patients with bladder cancer, between March 15, and May 20, 2020.

Patients were divided into two groups: those who received intravesical BCG due to bladder cancer (Study group) and those who did not receive BCG despite the diagnosis of bladder cancer (Control group).

Study group patients: In the urology service of our hospital, patients who received intra-cavitary BCG immunotherapy due to non-muscle-invasive

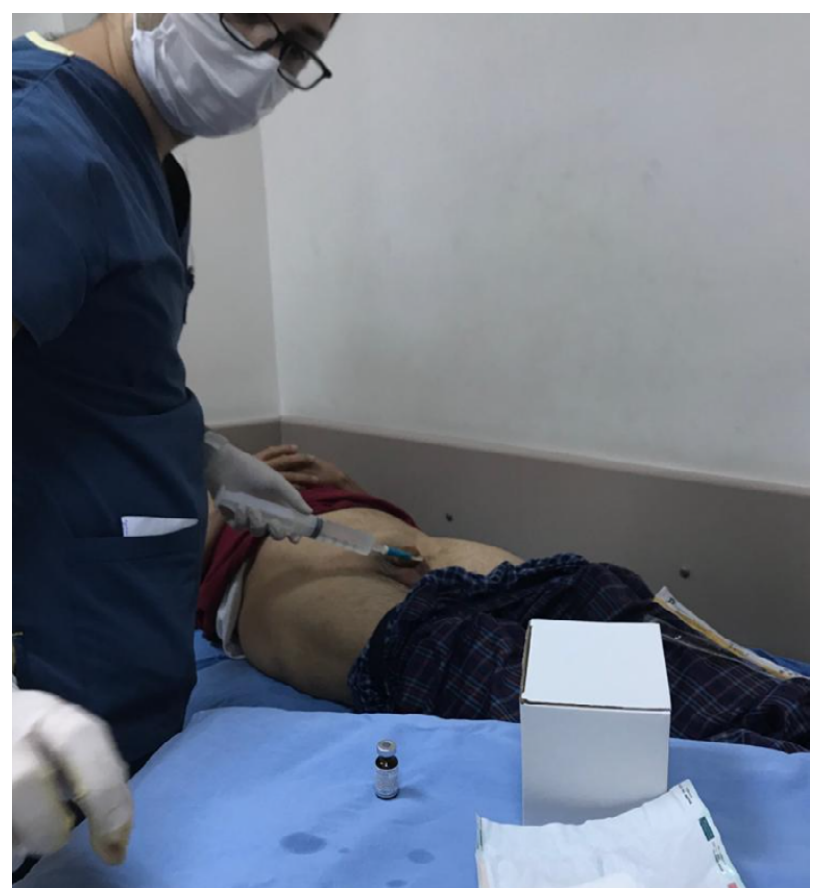

FIGURE 2. INTRAVESICAL BCG APPLICATION 
exchange epithelial cell bladder cancer were selected retrospectively.

- Bladder cancer was diagnosed as a result of histopathological examination of the tumoral area, which was observed by transurethral resection, in cystoscopy performed on patients with suspected bladder cancer. Patients diagnosed with non-invasive bladder cancer as a result of histopathological examination were divided into low-, medium-, and high-risk groups based on the pathological stage, gradient, and clinical course of the tumor. Intracavitary BCG immunotherapy was given to patients who were in the high-risk group. Patients in the low- and medium-risk group were treated with different methods that did not include immunotherapy.

- BCG application in the study group: After transurethral resection, intravesical ONCOTICE (2-8 x 108 CFU [Colony-Forming Unit]) Bacillus CalmetteGuérin $81 \mathrm{mg}$ Pasteur BCG was given to the non-muscle invasive group once a week for 6 weeks after transurethral resection. Afterward, intracavitary BCG administration was given as maintenance therapy to patients with 3-month intervals for 3 years, and once a week for 6 years intervals. Control group patients: Patients registered in the urology service of our hospital, diagnosed with lowrisk bladder cancer histopathologically, and living in the city of Sakarya during an epidemic without BCG or any other immune regulator treatment were selected retrospectively.

\section{Statistical analysis}

All analyses were performed in Epi-Info ver 6.0 (CDC-USA). Statistical analysis was performed using Independent Samples T-test and Yates correction chi-square test. A $P$ value $<0.05$ was accepted as significant.

The study was carried out upon receiving the approval of the Ethics Committee of the Sakarya University Faculty of Medicine (No: 71522473 /050.01.04/248).

\section{RESULTS}

A total of 334 patients were included in the study. The mean age of the 167 patients in the study group was $71.1 \pm 14.21$ (min. 38.0- max. 98.0 years), and 141 (84.4\%) were male. The mean age for the 167 patients in the control group was $70.5 \pm 13.8$ (min. 41.0 - max. 96.0 years), and 149 were male $(p>0.05)$ (Figure 3). COVID-19 was detected in 5 patients in

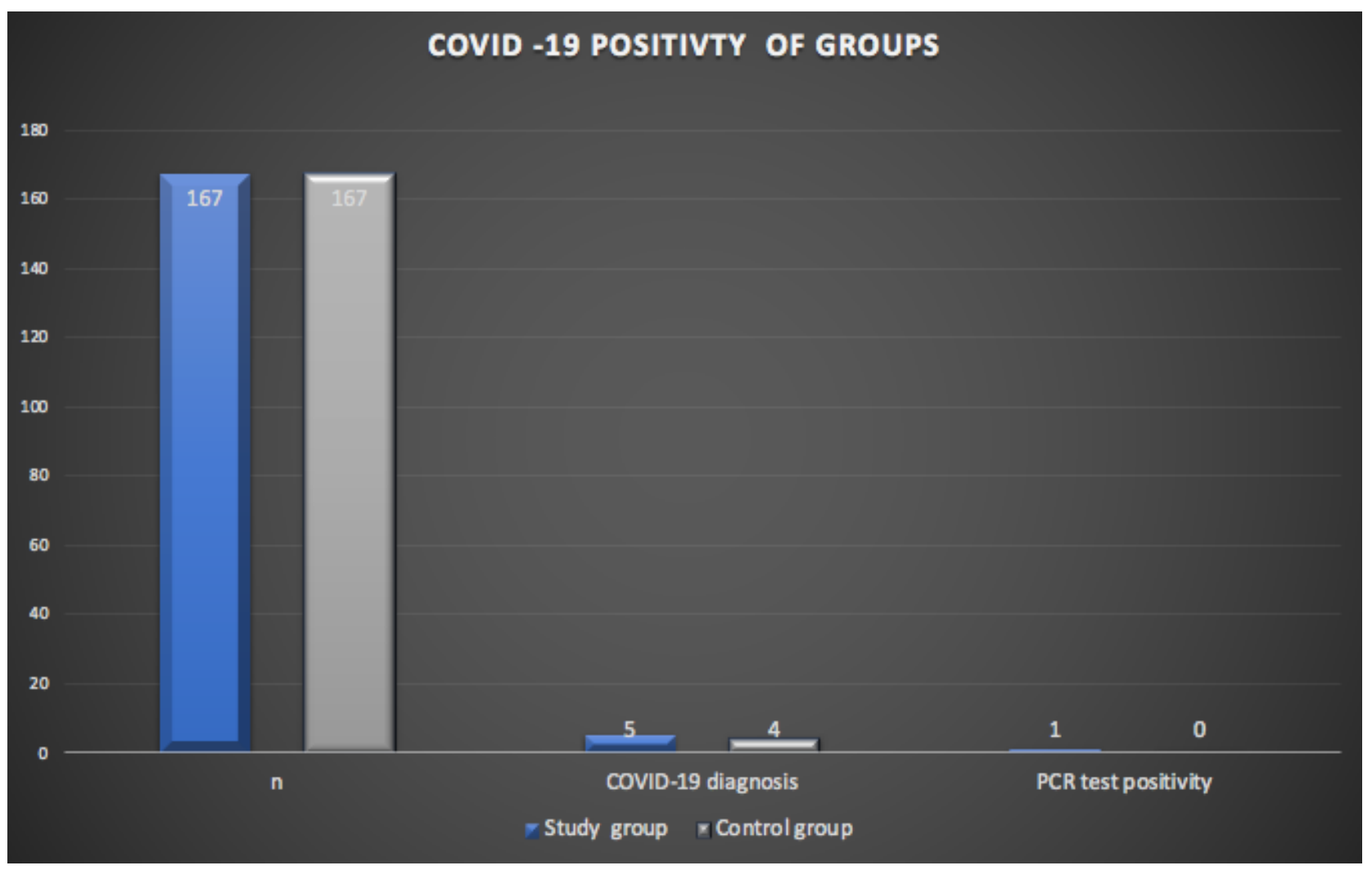

FIGURE 3. COVID-19 TEST POSITIVITY OF GROUPS 
TABLE 1. DEMOGRAPHIC AND CLINICAL CHARACTERISTICS OF PATIENTS

\begin{tabular}{l|l|l|l} 
Parameter & $\begin{array}{l}\text { Study } \\
\text { group }\end{array}$ & $\begin{array}{l}\text { Control } \\
\text { group }\end{array}$ & P-value \\
\hline $\mathrm{n}$ & 167 & 167 & $\mathrm{NA}$ \\
\hline Male & $141(84.4 \%)$ & $149(89.2 \%)$ & $>0.05$ \\
\hline Female & $26(15.5 \%)$ & $18(10.8 \%)$ & $>0.05$ \\
\hline Mean age & $71.1 \pm 14.21$ & $70.5 \pm 13.8$ & $>0.05$ \\
\hline COVID-19 diagnosis & $5(2.9 \%)$ & $4(2.3 \%)$ & $>0.05$ \\
\hline PCR test positivity & $1(0,05 \%)$ & 0 & NA \\
\hline $\begin{array}{l}\text { Mean age of COVID-19 } \\
\text { Positive patients }\end{array}$ & 70.04 & 73.02 & $>0.05$ \\
\hline NA: Not Applicable & & &
\end{tabular}

the BCG group and in 4 patient in the control group $(\mathrm{P}>0.05)$ (Table 1).

\section{DISCUSSION}

Numerous epidemiological, clinical, and immunological studies have shown that BCG vaccination affects immunity to infections, thereby reducing morbidity and mortality. BCG is reported to increase immunity to viral infections by inducing heterologous lymphocyte activation by increasing cytokine production, macrophage activity, T-cell responses, and antibody titers ${ }^{4}$. BCG has been used in intravesical immunotherapy of bladder cancers for nearly 40 years. It has been administered intravesically in recurrent superficial bladder cancers and has been reported to reduce cancer recurrence rates ${ }^{5}$. In a study, BCG vaccination has been shown to reduce the incidence of respiratory syncytial virus infection ${ }^{6}$.

BCG stimulates congenital immunity, and this can be important to create a defense against viral respiratory infections. This is a different route of administration than the arm, which is the standard. While the BCG vaccine protects against the herpes simplex virus type 2 (HSV2), subcutaneous administration of muramyl dipeptide (MDP), a component of the mycobacterium cell wall, protected against the vaccine virus and HSV 2 infections in mice ${ }^{7}$. However, in this study, patients receiving BCG received it administered into the bladder. Therefore, our findings do not fully demonstrate the effectiveness of standard therapy ${ }^{8}$.

BCG is a bacterial vaccine. It is not surprising that this vaccine does not sufficiently provide protection against a pervasive virus such as COVID-19. More importantly, the fact that our study group consisted of cancer patients is also important for limiting the effects of BCG on the immune system. However, the use of a cancer group and a control group also provides a comparison. After BCG vaccination, there was increased production of pro-inflammatory cytokines such as IL-1, tumor necrosis factor (TNF), and IL- $6{ }^{9}$. However, one of the most feared situations in COVID-19 patients who died is macrophage activation syndrome caused by the excessive increase of cytokines such as IL-1, IL-6, IL-8 in the blood. BCG vaccine, which is expected to be useful in this, may conversely harm this patient group ${ }^{10}$.

However, despite all this information, there is no clear evidence that the intravesical BCG vaccination protects people against COVID-19. Indeed, in this study, we found that the frequency of COVID19 in those who received intravesical BCG was not different from those who did not. According to our findings, we could not show the utility of intravesical BCG in the prevention of COVID-19. However, the data we obtained are based on the results of intravesical administration. The hypothesis that intra-dermal application can protect against COVID-19 needs to be tested in rigorous randomized clinical trials.

\section{Author's Contribution}

OK: Data analysis and interpretation, drafting the article, critical revision of the article, approval of the final version.

OK: Conception and design of the work, data analysis and interpretation, critical revision of the article, final of the final version.

AT; BU; HD; SY; EG: Data collection, data analysis and interpretation, critical revision of the article, approval of the final version to be published.

\section{RESUMO}

INTRODUÇão: Neste estudo retrospectivo, objetivou-se investigar a frequência de COVID-19 em pacientes com e sem aplicação de BCG por tumor de bexiga.

MÉTODOS: A presença de COVID-19 foi investigada em 167 pacientes com BCG e 167 sem câncer de bexiga. Todos os pacientes compativeis para infecção por COVID-19. Resumidamente, os pacientes foram incluídos no estudo com RT-PCR positivo para Sars-CoV-2 elou TC de tórax positivo para pneumonia viral entre março e maio de 2020. 
RESULTADOS: Um total de 334 pacientes foi incluído no estudo. A idade média dos 167 pacientes no grupo de estudo foi de 71,1 14,21

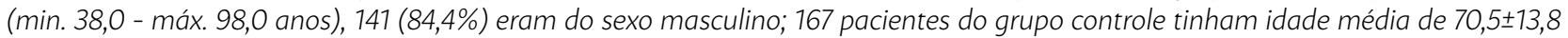
(min. 41,0 - máx. 96,0 anos) e 149 eram do sexo masculino ( $p>0,05)$. A COVID-19 foi detectada em cinco pacientes no grupo BCG e em um no grupo controle $(p>0,05)$.

CONCLUSÃo: A administração intravesical de BCG não diminui a frequência da infecção por COVID-19.

PALAVRAS-CHAVE: COVID-19. BCG intravesical.

\section{REFERENCES}

1. Sharma M, Surani S. Searching an Effective Therapy for the Coronavirus Pandemic: Do We See Light at the End of the Tunnel? [Internet]. Cureus. 2020. Available from: http://dx.doi.org/10.7759/cureus.7415

2. Witjes JA, Bruins HM, Cathomas R, Compérat EM, Cowan NC, Gakis G, et al. European Association of Urology Guidelines on Muscle-invasive and Metastatic Bladder Cancer: Summary of the 2020 Guidelines. Eur Urol [Internet]. 2020 Apr 29; Available from: http://dx.doi.org/10.1016/j. eururo.2020.03.055

3. Kumar J, Meena J. Demystifying BCG Vaccine and COVID-19 Relationship. Indian Pediatr [Internet]. 2020 Apr 30; Available from: https://www.ncbi. nlm.nih.gov/pubmed/32358227

4. Moorlag SICFM, Arts RJW, van Crevel R, Netea MG. Non-specific effects of BCG vaccine on viral infections. Clin Microbiol Infect. 2019 Dec;25(12):1473-8.

5. Iori F, Di Seri M, De Nunzio C, Leonardo C, Franco G, Spalletta B, et al. Long-term maintenance bacille Calmette-Guérin therapy in high-grade superficial bladder cancer. Urology. 2002 Mar;59(3):414-8.
6. Stensballe LG, Nante E, Jensen IP, Kofoed P-E, Poulsen A, Jensen H, et al. Acute lower respiratory tract infections and respiratory syncytial virus in infants in Guinea-Bissau: a beneficial effect of BCG vaccination for girls community based case-control study. Vaccine. 2005 Jan 26;23(10):1251-7.

7. Ikeda S, Negishi T, Nishimura C. Enhancement of non-specific resistance to viral infection by muramyldipeptide and its analogs. Antiviral Res. 1985 Aug;5(4):207-15.

8. O'Neill LAJ, Netea MG. BCG-induced trained immunity: can it offer protection against COVID-19? Nat Rev Immunol [Internet]. 2020 May 11; Available from: http://dx.doi.org/10.1038/s41577-020-0337-y

9. Kleinnijenhuis J, Quintin J, Preijers F, Joosten LAB, Ifrim DC, Saeed S, et al. Bacille Calmette-Guerin induces NOD2-dependent nonspecific protection from reinfection via epigenetic reprogramming of monocytes. Proc Natl Acad Sci U S A. 2012 Oct 23;109(43):17537-42.

10. Mehta P, McAuley DF, Brown M, Sanchez E, Tattersall RS, Manson J), et al. COVID-19: consider cytokine storm syndromes and immunosuppression. Lancet. 2020 Mar 28;395(10229):1033-4. 